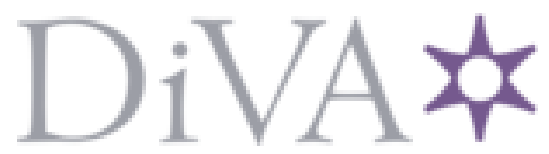

http://www.diva-portal.org

This is the published version of a paper presented at 18th Annual International Conference on Education, 16-19 May 2016, Athens, Greece..

Citation for the original published paper:

Olteanu, C. (2016)

Reflection and the object of learning.

In: Gregory T. Papanikos (ed.), Education Abstracts: Eighteenth Annual International

Conference on Education 16-19 May 2016, Athens, Greece (pp. 117-117). Athens Institute for

Education and Research (ATINER)

N.B. When citing this work, cite the original published paper.

Permanent link to this version:

http://urn.kb.se/resolve?urn=urn:nbn:se:Inu:diva-55689 


\section{Constanta Olteanu}

Professor, Linnaeus University, Sweden

\section{Reflection and the Object of Learning}

In the present paper, I present a model that can be used for supporting teachers' reflection on practical situations they are confronted with. The model is grounded in two concepts from variation theory: critical aspects and dimensions of variation. Analysis of the data allows for determination of what kind of reflection is used in teachers' professional development when working with algebra modules and the teachers' perceptions of the relevance and usefulness of the professional development concerning algebra modules. The results show that effective professional development focuses on improving instructional practice by giving teachers new knowledge and techniques for assessing learning with the ultimate goal of improving the learning of students. The results also show that the teachers practiced reflection-in and on-action. 